\title{
Credit Risk Analysis and Security Design*
}

\author{
Roman Inderst $^{\dagger} \quad$ Holger M. Müller ${ }^{\ddagger}$
}

November 2002

\footnotetext{
*We thank Andres Almazan, Jacqes Cremer, Darrell Duffie, Colin Mayer, Enrico Perotti, Patrick Rey, Tony Saunders, Raghu Sundaram, Jean Tirole, Ivo Welch, Jeff Wurgler, and seminar participants at NYU, Yale, Kellog, Rochester, UNC Chapel Hill, Wisconsin-Madison, LBS, LSE, Toulouse, Amsterdam, Frankfurt, Humboldt, FU Berlin, WZB Berlin, the Oxford Finance Summer Symposium (2002), and the European Summer Symposium in Financial Markets (ESSFM) in Gerzensee (2002) for helpful comments and suggestions. Inderst acknowledges financial support from the Financial Markets Group (FMG).

${ }^{\dagger}$ London School of Economics \& CEPR. Address: Department of Economics \& Department of Accounting and Finance, London School of Economics, Houghton Street, London WC2A 2AE. Email: r.inderst@lse.ac.uk.

${ }^{\ddagger}$ New York University \& CEPR. Address: Department of Finance, Stern School of Business, New York University, 44 West Fourth Street, Suite 9-190, New York, NY 10012. Email: hmueller@stern.nyu.edu.
} 


\section{Credit Risk Analysis and Security Design}

This paper considers the potential cost of subjective judgement and discretion in credit decisions. We show that subjectivity and discretion in the evaluation of borrowers create an

incentive problem on the part of the lender. The lender's incentives to accept or reject a borrower depend only on the value of her own claims, not on the total value of the project. Unless the lender obtains the full NPV her credit decision is too conservative, i.e., she uses too high a hurdle rate. Given this incentive problem we show that the unique optimal security is standard debt. Among all securities debt is the one that makes the lender the least conservative, thus providing her with (second-best) optimal incentives to trade off type- 1 and type- 2 errors. Among other things, this suggests that the common folk wisdom whereby giving banks equity makes them less cautious in their credit decisions is generally not correct. 


\section{Introduction}

Increasingly competitive margins, declining collateral values, and - last but not least - the new BIS II Capital Accord linking capital charges to credit risk exposures underscore the need for better and more sophisticated techniques to measure credit risk. Technological progress notwithstanding, a key factor in the credit decision is the human decision maker. E.g., Saunders and Allen (2002) note: "[T]he credit decision is left to the local or branch lending officer or relationship manager. Implicitly, this person's expertise, subjective judgement, and his weighting of certain key factors are the most important determinants in the decision to grant credit."

This paper considers the potential cost of subjective judgement and discretion in credit decisions. ${ }^{1,2}$ Specifically, we argue that subjectivity and discretion in credit decisions create an incentive problem on the part of the lender. Our model applies particularly to small business, commercial, or retail lending. The lender first offers a contract (e.g., bank $x$ advertises that the interest rate for a loan of type $y$ is $z$ per cent). The lender then analyzes the applicant's credit risk, and-based on the outcome of the analysis - either accepts or rejects the applicant. ${ }^{3}$ We make no specific assumption about the credit risk analysis, except that the lender's judgement and beliefs can be represented by a signal, where higher signal values indicate that the applicant has a better credit risk. Given the subjectivity of the lender's judgement we assume that the signal is not contractible. ${ }^{4}$ At the end of the day it is thus the lender - and only the lender - who

\footnotetext{
${ }^{1}$ Stein (2002) models the costs and benefits of "soft" information about borrowers in terms of its implications for the capital allocation and organizational design of banks. Our notion of subjective judgement and Stein's notion of soft information are closely related. As an example of soft information Stein gives the (subjective) beliefs of a loan officer as to whether the president of a company is honest and hardworking.

${ }^{2}$ The argument is different from the relationship banking literature where discretion is the basis for implicit, non-enforceable lending relationships (Boot, Greenbaum, and Thakor (1993)). In that literature discretion also entails costs (Sharpe (1990), Rajan (1992)), which warrants contractual solutions (von Thadden (1995)).

${ }^{3}$ This is the reduced form of an optimal mechanism. In the model we allow the lender to offer an arbitrarily large menu of contracts, from which she can choose a contract after performing the credit risk analysis. We show that the optimal menu from the lender's perspective contains a single contract. Incidentally, the contract derived in this paper is uniquely optimal for all feasible reservation utilities of the borrower. If instead of the lender making a take-it-or-leave-it-offer the lender and borrower were to bargain they would choose the same contract.

${ }^{4}$ All we need is that courts cannot perfectly replicate the lender's judgement. Since the judgement is subjective this is true by assumption. See Saunders and Allen (2002), who argue that subjectivity in credit decisions "makes comparability of rankings and decisions very difficult for an individual monitoring an expert's decision [...].”
} 
decides whether to give the loan or not.

Discretion in credit decisions implies that the lender's incentives to accept or reject the applicant depend on the value of her claims, and thus the contract in place. We show that unless the lender obtains the full NPV from the project her credit decision is too conservative. The (endogenously) optimal credit decision follows a simple cutoff rule: Accept all borrowers above the cutoff signal and reject all borrowers below it. The inefficiency is that the cutoff signal used by the lender lies strictly above the first-best cutoff signal where NPV is maximized. This is not driven by the fact that the signal is a noisy indicator of the applicant's credit risk - it holds equally if the signal is fully revealing. Neither is it driven by the contract in place - it holds for any type of contract. Finally, the result is not driven by private information on the part of the borrower. While our model naturally extends to situations in which the borrower has private information, our base model assumes that borrower and lender have common priors at the time when the borrower applies for the loan.

The optimal contract minimizes the inefficiency from excessive project rejection. The unique optimal contract in our model is a standard debt contract. Debt maximizes the lender's payoff in low cash-flow states, thereby maximizing her return from low-type projects, i.e., projects with a high probability mass on low cash-flow outcomes. Having less to loose from financing a low-type project the lender becomes less conservative and uses a lower cutoff signal. Precisely, the cutoff signal implemented by a debt contract is lower than that implemented by any other security, and therefore closest to the first-best value.

A related, but different way of viewing the role of debt is in terms of type- 1 and type- 2 errors. The first-best cutoff signal-i.e., the NPV rule - optimally trades off these two types of errors. By contrast, under the second-best cutoff signal the lender puts too much weight on type-1 errors, i.e., she worries too much about erroneously accepting a low-type project. The security design problem is therefore one-sided in the sense that the objective is to curb the lender's tendency to overweight type-1 errors. Debt, by offering the lender maximum downside protection, accomplishes this objective.

Our argument that debt implements (constrained) optimal credit decisions is both new and consistent with the widespread use of debt in situations where credit risk analysis is important. Various other rationales for debt have been proposed in the literature. ${ }^{5}$ Debt minimizes $e x$ -

\footnotetext{
${ }^{5}$ See Allen and Winton (1995) for a survey.
} 
post verification costs (Townsend (1979), Gale and Hellwig (1985)) or the deadweight loss from inflicting non-pecuniary penalties upon borrowers (Diamond (1984)). If there is ex-post moral hazard on the part of the borrower debt provides the borrower with incentives to work hard (Innes (1990)) or repay funds (Bolton and Scharfstein (1990), Hart and Moore (1998)). Finally, debt is optimal if the issuer has private information either before (Nachman and Noe (1994), formalizing the intuition in Myers and Majluf (1984)) or after the security design (DeMarzo and Duffie (1999), Biais and Mariotti (2001)).

In all of the above papers the problem originates with the borrower: He diverts cash flow, shirks, or sells overpriced securities. By contrast, in our model the problem is with the lender. Axelson (2002), Boot and Thakor (1993), and Fulghieri and Lukin (2001) also have this flavor. In Axelson's model a seller auctions off asset-backed securities to privately informed investors. The optimal security trades off the expected underpricing against the liquidity cost of retaining cash flow. By contrast, in our model the optimal security provides the lender with incentives (to lower the cutoff signal), much like the optimal contract in a moral hazard model provides the agent with incentives to work hard. In Boot and Thakor (1993) and Fulghieri and Lukin (2001) information production is costly. To make information production attractive firms issue information-sensitive claims like equity. We abstract from costly information production and focus exclusively on the problem of trading off type- 1 and type- 2 errors.

Our results also have implications for the policy debate surrounding the separation of banking and commerce in the U. S. There banks are - with few exceptions - forbidden to hold significant equity stakes in nonfinancial firms. Berlin (2000) summarizes the research agenda as follows: "Do restrictions against U.S. banks holding equity make a difference for banks' behavior? Are U.S. banks' borrowers at a disadvantage because their lenders are too cautious when evaluating project risks and too harsh when a borrower experiences financial difficulties?" While in our model lenders are indeed too cautious, this is not because they hold debt, but because they do not capture the full NPV from the project. In fact, we show that it is debt-not equity-that makes lenders the least cautious in their lending practice. ${ }^{6}$

Let us finally comment where we think our model applies best, and where it does not. It applies best to imperfectly competitive credit markets as, e.g., in the case of small-business

\footnotetext{
${ }^{6}$ Existing research examining whether banks should hold equity focuses on other issues, such as banks' behavior during debt workouts and periods of financial distress. See, e.g., Berlin, John, and Saunders (1996).
} 
lending, where small firms borrow primarily from their local bank. The local bank has an advantage over other lenders due to its familiarity with local conditions, superior knowledge of the firm, or simply greater proximity. Only if the firm is rejected by its local bank will it go to another lender. (See Section 4.7 for details.) And yet, the presence of other lenders puts a lower bound on the surplus which the local bank can extract. For this type of setting the core features of our model - debt, insensitivity of loan terms (but not loan availability) with respect to interim information, and a negative relation between credit market competition and loan availabilityare consistent with the available empirical evidence. ${ }^{7}$ On the other hand, our model applies less to large corporations for whom proximity, transaction costs, and local knowledge are less important. Such firms - in particular if the investment is large - might optimally solicit bids from several investors simultaneously, e.g., by conducting an auction. The model also has less to say about firms that have already established a reputation and have therefore access to other, potentially cheaper sources of funding such as public debt markets.

The rest of the paper is organized as follows. Section 2 introduces the model. Section 3 derives the optimal credit policy and optimal security. It also contains a discussion of the main differences between our model and other models of debt. Section 4 reconsiders some of the main assumptions and discusses their robustness. Section 5 concludes.

\section{The Model}

A penniless entrepreneur ("the borrower") has a project requiring an investment $k .{ }^{8}$ The investment is provided by a lender. Prior to making the investment the lender can assess the borrower's credit risk.

\subsection{Project Technology}

There are several possible project types denoted by $\theta \in \Theta$. While we assume that $\Theta$ is countable our results extend to arbitrary type sets. Types are denoted by $\theta \in \Theta:=\{1,2, \ldots, \bar{\theta}\}$, where $\bar{\theta}:=\infty$ if there are infinitely many types. A type- $\theta$ project generates a random, non-negative cash flow $x$ drawn from the distribution function $G_{\theta}(x)$ with support $X:=[\underline{x}, \bar{x}]$. We assume that $\bar{x}>\underline{x} \geq 0$, where $\bar{x}$ is either finite or infinite, and where $\underline{x}<k$. The density $g_{\theta}(x)$ is

\footnotetext{
${ }^{7}$ See Petersen and Rajan (1994) and Cetorelli and Gambera (2001).

${ }^{8}$ Section 4.4 considers projects with variable investment size.
} 
continuous and positive for all $x \in X$, implying that it has expected value $\mu(\theta)>0$. Continuity of the density is a standard assumption and implies that we can restrict attention to deterministic contracts. All our results extend to the case where $g_{\theta}(x)=0$ at the boundaries of $X$.

We assume that high-type projects are "better" than low-type projects in the sense that they put strictly more probability mass on high cash flows in the sense of the Monotone Likelihood Ratio Property (MLRP).

Assumption 1. For any pair $\left(\theta, \theta^{\prime}\right) \in \Theta$ with $\theta^{\prime}>\theta$ the ratio $g_{\theta^{\prime}}(x) / g_{\theta}(x)$ is strictly increasing in $x$ for all $x \in X$.

MLRP is a common assumption in contracting models and implies that high cash flows are more likely to be generated by high-type projects than by low-type projects. It is satisfied by many standard distributions. For a discussion and economic interpretation see Milgrom (1981).

\subsection{Credit Risk Analysis}

As outlined in the Introduction, we assume that the lender's subjective judgement and beliefs can be represented by a noncontractible signal $s$. The signal has support $S:=[0,1]$ and is drawn from the distribution function $F_{\theta}(s)$ with continuous density $f_{\theta}(s)$, where $f_{\theta}(s)>0$ for all $s \in(0,1)$. The assumptions concerning the density ensure that even a small change in the contract has an effect on the lender's credit decision. While we believe the assumption that the signal is a noisy indicator of the borrower's type is realistic, it is not critical for our results. In Section 4.5 we show that the model can be rephrased as a model in which there is a continuum of types and the signal is fully revealing.

There are at least two potential inefficiencies associated with credit risk analysis: (i) committing type- 1 and type-2 errors, i.e., misclassifying bad projects as good ones and vice versa, and (ii) devoting too little or too much time and effort to the analysis. The second type of inefficiency has been studied extensively in the literature (e.g., Manove, Padilla, and Pagano (2001), Hauswald and Marquez (2001), Fulghieri and Lukin (2001)). To focus on the first type of inefficiency we assume that the credit risk analysis is costless.

Nothing in this paper relies on the borrower having private information. To underscore this point we assume that at the time of the loan application the borrower and lender have common priors $h(\theta)$, where $h(\theta)>0$ for all $\theta \in \Theta$. In Section 4.6 we show that our results naturally extend to situations in which the borrower has private information. 
One realistic implication of the fact that the borrower and lender have common priors is that the credit risk analysis generates new, valuable information that has been unavailable previously (rather than merely providing the lender with information the borrower already has). After all, it is unlikely that the borrower's estimate of the project's risk is as accurate as that of an experienced lender. One reason why the lender might be better able to judge the project risk is that he holds other loans in the same industry (Boot and Thakor (2000)). As we said above, however, all our results hold if the borrower has private information at the time of the loan application.

It is reasonable to assume that high-type projects are more likely to generate high signals than low-type projects. Specifically, we assume that high-type projects put strictly more probability mass on high signals than low-type projects in the sense of MLRP.

Assumption 2. For any pair $\left(\theta, \theta^{\prime}\right) \in \Theta$ with $\theta^{\prime}>\theta$ the ratio $f_{\theta^{\prime}}(s) / f_{\theta}(s)$ is strictly increasing in $s$ for all $s \in S$.

Given a signal $s$ the lender has posterior beliefs that the borrower is of type $\theta$ with probability

$$
h(\theta \mid s):=\frac{h(\theta) f_{\theta}(s)}{\sum_{\theta^{\prime} \in \Theta} h\left(\theta^{\prime}\right) f_{\theta^{\prime}}(s)} .
$$

The conditional expected cash flow given the signal $s$ is then $\sum_{\theta \in \Theta} \mu(\theta) h(\theta \mid s)$.

In a slight abuse of notation we denote the distribution of cash flows conditional upon observing the signal by $G(x \mid s)$. The associated density is $g(x \mid s):=\sum_{\theta \in \Theta} h(\theta \mid s) f_{\theta}(x)$. High-type projects are both more likely to generate higher cash flows and higher signals. Note, however, that this relation is stochastic. It may well be that the actual cash flow generated by a high-type project is higher than that generated by a low-type project but the signal is lower. Together, Assumptions 1 and 2 imply that the conditional cash-flow distribution $G(x \mid s)$ satisfies MLRP. ${ }^{9}$ This also implies that the conditional expected cash flow $\sum_{\theta \in \Theta} \mu(\theta) h(\theta \mid s)$ is strictly increasing in $s$.

The property that $G(x \mid s)$ satisfies MLRP is slightly stronger than what we need. The benefit, however, is that it permits a short, and straightforward proof that debt is optimal. In

\footnotetext{
${ }^{9}$ MLRP holds if and only if $g\left(x^{\prime} \mid s^{\prime}\right) g(x \mid s)>g\left(x^{\prime} \mid s\right) g\left(x \mid s^{\prime}\right)$ holds for all signals $s^{\prime}>s$ and all cash flows $x^{\prime}>x$. Using the definition of $g(x \mid s)$, this is equivalent to requiring that$$
\sum_{\theta>\sup \Theta, \theta^{\prime}>\theta} h\left(\theta^{\prime}\right) h(\theta)\left[f_{\theta^{\prime}}\left(x^{\prime}\right) f_{\theta}(x)-f_{\theta^{\prime}}(x) f_{\theta}\left(x^{\prime}\right)\right]\left[g_{\theta^{\prime}}\left(s^{\prime}\right) g_{\theta}(s)-g_{\theta^{\prime}}(s) g_{\theta}\left(s^{\prime}\right)\right]>0,
$$

which holds by Assumptions 1 and 2 .
} 
Sections 4.2-4.3 we show that debt remains optimal if Assumptions 1 and 2 are relaxed.

Finally, to rule out the trivial case where the optimal credit policy is independent of the signal we assume that investing is unprofitable if $s=0$ and profitable if $s=1$. That is, we assume that $\sum_{\theta \in \Theta} \mu(\theta) h(\theta \mid s)<k$ if $s=0$ and $\sum_{\theta \in \Theta} \mu(\theta) h(\theta \mid s)>k$ if $s=1 .^{10}$

\subsection{Lending Process}

The sequence of events is as follows. The lender publicly offers a contract specifying a repayment $t(x)$. For example, bank $x$ might advertise that the interest rate for a loan of type $y$ is $z$ per cent. The borrower then decides whether to apply for the loan. If the borrower applies the lender evaluates the borrower's credit risk. Based on the signal the lender then either accepts or rejects the borrower. (If the borrower is accepted he can still opt out. Below we show that this is never optimal, however.)

We assume that only borrowers who have been accepted receive a payment from the lender. For instance, courts might be unable to distinguish between a rejected applicant and somebody who never applied. In this case a payment conditional upon rejection is not feasible. Second, such payments might attract fraudulent entrepreneurs, or "fly-by-night operators" (Rajan (1992), von Thadden (1995)), i.e., applicants without a real investment opportunity who know for sure they will be rejected. The only reason why these applicants would apply is to cash in the payment. In this case a payment upon rejection is feasible but not optimal. ${ }^{11}$ This also rules out that the lender "buys" the borrower's project before evaluating its credit risk.

Although the contract cannot directly condition on the signal the lender could, in principle, reveal the signal by choosing a contract from a prespecified menu after performing the credit

\footnotetext{
${ }^{10}$ This can be endogenized. It holds, for instance, if (i) the lowest-type project $\theta=1$ has a negative NPV while projects with a sufficiently high $\theta$ have a positive NPV, and (ii) the signal is sufficiently informative at the boundaries. The latter statement can be formalized by assuming that at the lower boundary $s=0$ it holds that $f_{\theta}(0)=0$ if $\theta>1$ and $f_{\theta}(0)>0$ if $\theta=1$, while at the upper boundary $s=1$ it holds that $f_{\theta}(1)=0$ if $\theta<\bar{\theta}$ and $f_{\theta}(1)>0$ if $\bar{\theta}=1$. (If $\bar{\theta}=\infty$ then $f_{\theta}(1)=0$ must hold for all sufficiently low values of $\theta$.)

${ }^{11}$ More precisely, suppose fraudulent entrepreneurs have projects that yield a zero payoff for sure. The lender finds out whether the entrepreneur is fraudulent only by performing the credit risk analysis. (The credit risk analysis includes an assessment of the entrepreneur's books and business plan.) Stipulating a payment upon rejection would attract all fraudulent entrepreneurs in the population. By making the pool of fraudulent entrepreneurs sufficiently large we can rule out the optimality of such payments. Note that if the payment were made to a third party this party would have an incentive to collude with a fraudulent entrepreneur.
} 
risk analysis. We consider this possibility in Section 4.1. There we show that the unique optimal menu consists of a single contract, implying that all accepted borrowers obtain the same terms. This does not mean that the terms of the contract will be invariant with respect to project risk. Borrowers with different prior distributions $h(\theta)$-and hence different ex-ante expected cash flows $\sum_{\theta \in \Theta} h(\theta) \mu(\theta)$-will naturally obtain different contracts. Similarly, contracts will vary with respect to investment size and other ex-ante characteristics. Hence our model does not predict that we should observe only a single contract per lender. On the contrary, there should be as many contracts as there are borrowers with different ex-ante characteristics, i.e., prior distribution $h(\theta)$ or investment size $k$. What our model predicts, however, is that once borrowers are grouped into different categories any further discrimination based on interim information (i.e., the signal) will be crude and take place in the form of an accept or reject decision. E.g., Saunders and Thomas (2001) note: "[L]oan decisions made for many types of retail loans are reject or accept decisions. All borrowers who are accepted are often charged the same rate of interest and by implication the same risk premium. [...] In the terminology of finance, retail customers are more likely to be sorted or rationed by loan quantity restrictions rather than by price or interest rate differences." Similarly, Petersen and Rajan (1994) - in their study of small business loans - find that the rate charged on a loan is not sensitive to measures of information generated about a borrower, while the availability of credit is.

In our model insensitivity of loan terms with respect to interim information arises endogenously as part of an optimal mechanism. Alternatively, we could assume it by asking what is the optimal "robust" security that works well for a variety of different borrowers (as in, e.g., DeMarzo and Duffie (1999)). The reason could be that fine-tuning is costly or that discretion regarding loan terms invites rent-seeking by the applicant or collusion between the loan officer and applicant. Whether the insensitivity with respect to interim information is endogenous or assumed is not important for our purpose.

While the repayment scheme must satisfy $t(x) \leq x$ we explicitly allow transfers from the lender to the borrower. We finally invoke the assumption that the repayment to the lender must be nondecreasing in the realized cash flow.

Assumption 3: $t(x)$ is nondecreasing.

Assumption 3 is standard (e.g., Innes (1990), Nachman and Noe (1994), DeMarzo and Duffie (1999)). The literature provides several arguments for why $t(x)$ should be nondecreasing. One 
is that otherwise the borrower could make an ex-post arbitrage gain by borrowing cash to boost the project outcome. (This is not inconsistent with the assumption that the borrower cannot divert or steal cash flow since in this case he would want to add cash flow.) Another argument is that if $t(x)$ were decreasing the lender might have an incentive to negatively influence the project outcome e.g., by withholding vital support. See Innes (1990) for a discussion.

While we assume that the lender makes the contract offer we explicitly want to leave open the possibility that the surplus is shared between the borrower and lender. We do this by assuming that in expectation the borrower must receive $\bar{V} \geq 0$. There are many reasons why the borrower might be able to capture a share of the surplus, such as market power or incentive problems. ${ }^{12}$ Alternatively, instead of having the lender make a take-it-or-leave-it offer we could assume that $t(x)$ is the outcome of a bargaining game where borrower and lender alternate in making offers. If the lender is not infinitely patient - e.g., because as an intermediary she must pay interest on her funds - the borrower will automatically capture a share of the surplus, implying that $\bar{V}>0$ (Binmore, Rubinstein, and Wolinsky (1986)). The particular story underlying $\bar{V}$ is not important for our purpose. We thus adopt an agnostic view by taking $\bar{V}$ as given and performing the analysis for all feasible values of $\bar{V}$. The only case where our model has nothing interesting to say is if the lender can appropriate 100 per cent of the surplus. We believe this is a rare situation, however. See also Section 4.7 where we sketch how $\bar{V}$ might arise from competition in the credit market.

If the borrower's outside option exceeds $\bar{V}$ there is no scope for lending: Upon rejection the borrower would obtain more than what he gets from applying in the first place. To provide a role for lending we therefore assume that the borrower's utility if he is rejected is less than $\bar{V}$. As the borrower receives $\bar{V}$ in expectation this implies that his utility if he is accepted must be greater than $\bar{V}$, and therefore greater than his utility if he is rejected. Consequently, a borrower who is accepted will never opt out. For expositional convenience we normalize the borrower's utility following rejection to zero. All we need, however, is a wedge between the borrower's utility if he is accepted and his utility if he is rejected. ${ }^{13}$

\footnotetext{
${ }^{12}$ See Inderst and Müller (2002b) for a model endogenizing $\bar{V}$ as a function of capital market competition. For a model in which surplus sharing arises from incentive problems see Holmström and Tirole (1997).

${ }^{13}$ If the lender is a monopolist this is innocuous. If the borrower can approach another lender after being rejected it suffices to assume that the utility from this is $\delta \bar{V}$, where $\delta<1$ reflects time value of money, search costs, or switching costs. Alternatively, $\delta<1$ may reflect the cost of disclosing critical information to (yet)
} 


\section{Optimal Credit Policy and Security Design}

The analysis proceeds in two steps. In the first step we derive the lender's optimal credit policyi.e., her accept or reject decision after observing the signal $s$ - for a given contract $t(x)$. In the second step we derive the optimal contract. We finally point out the differences between our model and other models of debt.

\subsection{Optimal Credit Policy}

High signals are good news in the sense that they put more more probability mass on high cash flows. Accordingly, the optimal credit policy follows a simple cutoff rule: accept all projects above some cutoff signal and reject all projects below it. We begin with the first-best credit policy where the total surplus, or NPV, is maximized.

Lemma 1. The first-best credit policy is to accept if $s>s^{F B}$ and to reject if $s<s^{F B}$, where the cutoff signal satisfies $s^{F B} \in(0,1)$. If $s=s^{F B}$ both acceptance and rejection are optimal. The cutoff signal is unique and given by

$$
\sum_{\theta \in \Theta} \mu(\theta) h\left(\theta \mid s^{F B}\right)=k
$$

Proof. By Assumptions 1 and 2 and continuity of $f_{\theta}(s)$ the conditional expected cash flow $\sum_{\theta \in \Theta} \mu(\theta) h(\theta \mid s)$ is continuous and strictly increasing in $s$. The rest follows from the fact that $\sum_{\theta \in \Theta} \mu(\theta) h(\theta \mid 0)<k$ and $\sum_{\theta \in \Theta} \mu(\theta) h(\theta \mid 1)>k$. Q.E.D.

The first-best credit policy is simply the NPV rule, which prescribes to accept a project if and only if its NPV is nonnegative. The cutoff signal $s^{F B}$ is the signal at which the NPV is zero or - in terms of equation (2) - the signal at which the conditional expected cash flow (left-hand side in (2)) equals the investment cost (right-hand side). Since the left-hand side in (2) is increasing in $s$ the NPV is positive if $s>s^{F B}$ and negative if $s<s^{F B}$.

As the signal is not contractible there is no simple way to implement the first-best credit policy. The lender's incentives to accept or reject the project will then depend on her expected payoff, and thus on the contract in place. We now formally characterize the second-best credit

another lender, which may increase the probability of leakage to the borrower's competitors (Yosha (1995)). See also Section 4.7, where we sketch a model in which the wedge between the borrower's utility if he is accepted and his utility if he is rejected arises from the advantage of local banks over more distant lenders. 
policy, i.e., the credit policy chosen by the lender given some contract $t(x)$. Denote the lender's expected payoff from a type- $\theta$ project by

$$
U_{\theta}(t):=\int_{x \in X} t(x) g_{\theta}(x) d x
$$

The lender's optimal credit policy is to accept if and only if her expected payoff conditional on the signal $s$ exceeds the investment cost $k$. As higher signals imply a more favorable cash-flow distribution in the sense of MLRP and the repayment scheme $t(x)$ is nondecreasing the lender's conditional expected payoff is strictly increasing in $s .{ }^{14}$ The second-best credit policy thus also involves a cutoff rule: The lender accepts all projects above the cutoff signal $s^{S B}(t(x))$. For expositional convenience we simply write $s^{S B}$.

If $t(x)$ is small it might be that the second-best cutoff signal is $s^{S B}=1$. If the actual signal is $s=1$ the lender is then either indifferent between accepting and rejecting (if $\sum_{\theta \in \Theta} U_{\theta}(t) h(\theta \mid$ $1)=k$ ) or she strictly prefers to reject (if $\sum_{\theta \in \Theta} U_{\theta}(t) h(\theta \mid 1)<k$ ). To keep the optimal credit policy simple we assume that in case of indifference the lender rejects. As this is a zero-probability event this assumption is without loss of generality.

Lemma 2. The lender's optimal-or second-best-credit policy is to accept if $s>s^{S B}$ and to reject if $s \leq s^{S B}$, where the cutoff signal satisfies $s^{S B} \in(0,1]$. If $\sum_{\theta \in \Theta} U_{\theta}(t) h(\theta \mid 1) \leq k$ the cutoff signal is $s^{S B}=1$, while if $\sum_{\theta \in \Theta} U_{\theta}(t) h(\theta \mid 1)>k$ the cutoff signal is $s^{S B} \in(0,1)$, where $s^{S B}$ is unique and given by

$$
\sum_{\theta \in \Theta} U_{\theta}(t) h\left(\theta \mid s^{S B}\right)=k
$$

Proof. By Assumption 3, $t(x)$ is nondecreasing. If $t(x)$ is "flat" it necessarily holds that $t(x) \leq \underline{x}$, implying that $U_{\theta}(t)<k$ for all $\theta \in \Theta$, which makes it optimal to always reject. In all other cases $t(x)$ is strictly increasing over a set of positive measure. By Assumption 1, $U_{\theta}(t)$ is then strictly increasing in $\theta$. In conjunction with Assumption 2 and continuity of $f_{\theta}(s)$ this implies that the lender's conditional expected payoff $\sum_{\theta \in \Theta} U_{\theta}(t) h(\theta \mid s)$ is continuous and strictly increasing in $s$. Finally, since $U_{\theta}(t) \leq \mu(\theta)$ and $\sum_{\theta \in \Theta} \mu(\theta) h(\theta \mid 0)<k$, it holds that $\sum_{\theta \in \Theta} U_{\theta}(t) h(\theta \mid 0)<k$. Existence and characterization of $s^{S B}$ follow immediately. Q.E.D.

\footnotetext{
${ }^{14}$ Since $G(x \mid s)$ satisfies MLRP it also satisfies First-Order Stochastic Dominance. For any nondecreasing function $t(x)$ the conditional expected payoff is then increasing in $s$. (This includes as a special case the conditional expected cash flow $\sum_{\theta \in \Theta} \mu(\theta) h(\theta \mid s)$, which corresponds to the function $\left.t(x)=x\right)$.
} 
If the lender's conditional expected payoff at $s=1$ is less than or equal to the investment cost the lender's optimal credit policy is to reject for all $s \leq 1$. Conversely, if the lender's conditional expected payoff at $s=1$ is greater than $k$ there exists a value $s^{S B} \in(0,1)$ at which the conditional expected payoff is equal to $k$, while it is greater than $k$ for all $s>s^{S B}$ and smaller than $k$ for all $s<s^{S B}$.

Comparing (2) and (3) shows that the first- and second-best cutoff signals are identical if and only if $U_{\theta}(t)=\mu(\theta)$, i.e., if and only if the lender gets the full NPV from the project. Is the lender too conservative or too lenient under the second-best credit policy? Suppose the lender does not get the full NPV. It then holds that $t(x)<x$ on a set of positive measure, implying that $U_{\theta}(t)<\mu(\theta)$ for all $\theta$. By (2) we have

$$
\sum_{\theta \in \Theta} U_{\theta}(t) h\left(\theta \mid s^{F B}\right)<\sum_{\theta \in \Theta} \mu(\theta) h\left(\theta \mid s^{F B}\right)=k
$$

implying that the lender does not break even at $s=s^{F B}$. Since the lender's conditional expected payoff is strictly increasing in $s$ this implies that her break-even signal $s^{S B}$ must lie strictly above $s^{F B}$. In other words, under the second-best credit policy the lender is too conservative relative to the first-best benchmark.

Lemma 3. Unless the lender gets the full NPV from the project her credit policy is too conservative, i.e., the second-best cutoff signal $s^{S B}$ lies strictly above $s^{F B}$.

For all signals $s \in\left[s^{F B}, s^{S B}\right)$ the lender's conditional expected payoff is negative. Implementing the first best would therefore require forcing the lender to finance projects under which she does not break even given her updated beliefs $h(\theta \mid s)$.

Figure 1 provides a graphical illustration of Lemma 1. The conditional expected project cash flow is denoted by $\sum_{\theta \in \Theta} \mu(\theta) h(\theta \mid s)=: a(s)$ while the conditional expected payoff of the lender is denoted by $\sum_{\theta \in \Theta} U_{\theta}(t) h(\theta \mid s):=b(s)$. Assumptions 1-3 imply that both $a(s)$ and $b(s)$ are strictly increasing in $s$. Moreover, $U_{\theta}(t)<\mu(\theta)$ implies that $a(s)$ must lie above $b(s)$ for all $s$. From the definitions of the first- and second-best cutoff signals, (2)-(3), it is then immediate that $s^{S B}>s^{F B}$.

The argument that the lender is too conservative is fairly general, and does not hinge on Assumptions 1-3. In particular, it does not hinge on the asssumption that $t(x)$ is nondecreasing. This follows immediately from the observation that if $t(x)<x$ on a set of positive measure it 


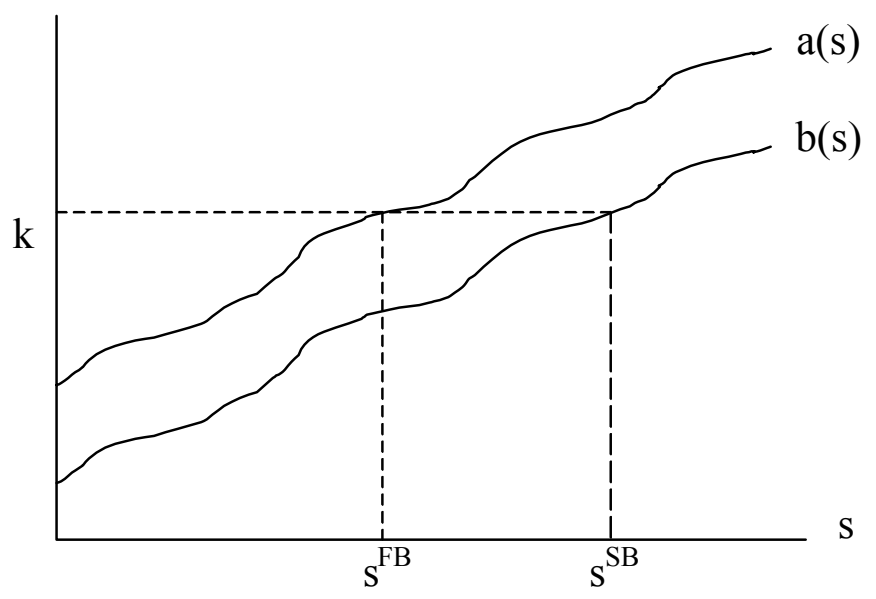

Figure 1: First- and Second-Best Cutoff Signal.

necessarily holds that

$$
\sum_{\theta \in \Theta} U_{\theta}(t) h(\theta \mid s)<\sum_{\theta \in \Theta} \mu(\theta) h(\theta \mid s),
$$

for all $s$, i.e., the lender's conditional expected payoff is strictly less than the conditional expected project cash flow for any signal $s \leq 1$. Hence if at $s=\hat{s}$ it is true that $\sum_{\theta \in \Theta} U_{\theta}(t) h(\theta \mid \hat{s})>k$, then it must also be true that $\sum_{\theta \in \Theta} \mu(\theta) h(\theta \mid \hat{s})>k$, but not vice versa. In words, if the second-best credit policy prescribes to accept the project at $s=\hat{s}$ the first-best credit policy will also prescribe acceptance at that signal. The reverse, however, is generally not true. Hence even without Assumptions 1-3 the lender will be too conservative in the sense that the set of signals leading to acceptance is strictly smaller than the corresponding set under the first best. Assumptions 1-3 merely ensure that the optimal credit policy can be characterized by a simple cutoff rule. ${ }^{15}$ "Being too conservative" then has the convenient and intuitive interpretation that the lender uses too high a cutoff signal.

ExAmple. Suppose there are two types, $\theta=1,2$ (low- and high-type projects). By Assumptions 1 and 3 we have that $U_{1}(t)<U_{2}(t)$ (unless $t(x)$ is a constant), i.e., the lender's expected payoff from the low-type project is less than from the high-type project. The lender's conditional expected payoff given the signal $s$ is

$$
U_{1}(t) h(1 \mid s)+U_{2}(t)[1-h(1 \mid s)]
$$

\footnotetext{
${ }^{15}$ While the statement that the lender is too conservative holds independently of Assumptions 1-3, these assumptions play an important role for the optimal security design in the following subsection.
} 
Hence the lender's conditional expected payoff is a weighted average of $U_{1}(t)$ and $U_{2}(t)$, where the weight $h(1 \mid s)$ associated with $U_{1}(t)$ is decreasing in $s$. Unless $t(x)=x$ the lender's expected payoff at $s=s^{F B}$ is strictly less than $k$. To make it equal to $k$ the lender must decrease the weight $h(1 \mid s)$ associated with $U_{1}(t)$ and increase the weight $1-h(1 \mid s)$ associated with $U_{2}(t)$. In other words, the lender must increase the cutoff signal, implying that $s^{S B}>s^{F B}$.

\subsection{Optimal Security Design}

The preceding analysis suggests that there exist two cases, albeit the first is merely the limiting case of the second. If $\bar{V}=0$ the lender obtains the full NPV, which implies the (optimal) contract is trivially $t(x)=x$. The credit policy in this case is first-best efficient.

By contrast, if $\bar{V}>0$ it holds that $t(x)<x$ on a set of positive measure, implying that the credit policy is inefficient. The optimal contract minimizes this inefficiency. Formally, the optimal contract maximizes the lender's expected payoff

$$
U(t):=\sum_{\theta \in \Theta} h(\theta)\left[1-F_{\theta}\left(s^{S B}\right)\right] U_{\theta}(t)
$$

subject to the constraint that in expectation the borrower receives at least $\bar{V}$ :

$$
V(t):=\sum_{\theta \in \Theta} h(\theta)\left[1-F_{\theta}\left(s^{S B}\right)\right] V_{\theta}(t) \geq \bar{V}
$$

where $s^{S B}$ is defined in Lemma 2. The borrower rationally anticipates the lender's choice of cutoff signal as a function of the contract $t(x)$. Accordingly, the borrower's ex-ante utility $V(t)$ equals $\sum_{\theta \in \Theta} h(\theta)\left[1-F_{\theta}\left(s^{S B}\right)\right] V_{\theta}(t)$, where $h(\theta)$ is the prior probability that the borrower is of type $\theta, 1-F_{\theta}\left(s^{S B}\right)$ is the probability that a type- $\theta$ borrower is accepted, and $V_{\theta}(t):=$ $\int_{x \in X}[x-t(x)] g_{\theta}(x) d x$ is the expected payoff of a type- $\theta$ borrower who is accepted. Clearly, if $\bar{V}$ is too large the lender cannot break even. In all other cases a nontrivial contract under which the borrower is accepted with positive probability exists. In the following we assume that $\bar{V}$ is sufficiently small in the sense just described.

In equilibrium the individual rationality constraint (4) binds, implying that any surplus in excess of $\bar{V}$ accrues to the lender. As a claimant to the residual surplus the lender optimally minimizes the efficiency loss from excessive rejection. ${ }^{16}$ Standard debt accomplishes this objective. Subject to the constraint that $t(x)$ be nondecreasing a debt contract maximizes the

\footnotetext{
${ }^{16}$ The same would hold if the borrower were to make the contract offer. The argument for why debt is optimal in our model is thus independent of who makes the contract offer.
} 
lender's payoff in low cash-flow states. Since low cash-flow states are more likely under low-type projects debt maximizes the lender's payoff from low-type projects. Having less to loose from financing a low-type project the lender is less cautious and uses a lower cutoff signal. Specifically, the cutoff signal implemented under a debt contract - and hence the efficiency loss from excessive rejection - is lower than under any other contract. And yet, as long as $\bar{V}$ is positive the second-best cutoff signal remains strictly above the first best.

Proposition 1. The unique optimal contract is a standard debt contract. That is, there exists a repayment level $R>k$ such that the unique optimal contract is $t(x)=x$ for all $x \leq R$ and $t(x)=R$ for all $x>R$.

If $\bar{V}=0$ the optimal repayment level is $R=\bar{x}$ and the associated credit policy is first-best efficient. By contrast, if $\bar{V}>0$ the optimal repayment level is $R<\bar{x}$ and the lender is too conservative relative to the first best.

Proof. The lender's conditional expected payoff given the signal $s$ can be written in a more compact form as $\int_{\underline{x}}^{\bar{x}} t(x) g(x \mid s) d x$, where $g(x \mid s)$ satisfies MLRP. In a slight abuse of notation denote the prior beliefs that the signal is $s$ by $f(s):=\sum_{\theta \in \Theta} h(\theta) f_{\theta}(s)$. As borrower and lender have common priors about $\theta$ they also have common beliefs about $s$.

The case where $\bar{V}=0$ is evident. The lender will get the entire surplus - hence the optimal contract is $t(x)=x$ for all $x$ (or debt with repayment level $R=\bar{x}$ ). The statement regarding the credit policy follows from Lemma 3.

Suppose next that $\bar{V}>0$. The statement regarding the lender's conservativism was proven in Lemma 3. In what follows we show that for any non-debt contract $t:=t(x)$ we can find a debt contract $\tilde{t}=\tilde{t}(x):=\min \{x, R\}$ that is preferred by the lender and satisfies the borrower's participation constraint. Let $s^{S B}(t)$ denote the cutoff signal implemented by $t$. We construct $\tilde{t}$ by requiring that-holding the cutoff signal constant at $s^{S B}(t)-\tilde{t}$ yields the same expected payoff to the lender as $t$. Given $t$ the debt contract $\tilde{t}$ is uniquely defined by

$$
\int_{s^{S B}(t)}^{1}\left[\int_{\underline{x}}^{\bar{x}} z(x) g(x \mid s) d x\right] f(s) d s=0
$$

where $z(x):=\tilde{t}(x)-t(x)$. Since we are holding the cutoff signal constant the total surplus also remains constant. Accordingly, if the lender's expected payoff is the same under $t$ and $\tilde{t}$ the borrower's expected payoff must also be the same under the two contracts.

As $\tilde{t} \neq t$ and the lender's conditional expected payoff is continuous in $s$ under both $t$ and $\tilde{t}$ it follows from (5) that there exists a signal $s^{\prime} \in\left(s^{S B}(t), 1\right)$ such that $\int_{\underline{x}}^{\bar{x}} z(x) g\left(x \mid s^{\prime}\right) d x=0$. 
Moreover, as $t$ is nondecreasing by Assumption 3 and $\tilde{t}$ is a debt contract (that gives the lender everything in low cash-flow states) this also implies that there exists a cash flow $\hat{x} \in(\underline{x}, \bar{x})$ such that $z(x) \geq 0$ for all $x<\hat{x}$ and $z(x) \leq 0$ for all $x>\hat{x}$, where the inequalities are strict over sets of positive measure. As $G(x \mid s)$ satisfies MLRP and $s^{S B}(t)<s^{\prime}$ we have that $g\left(x \mid s^{S B}(t)\right) / g\left(x \mid s^{\prime}\right)$ is strictly decreasing in $x$. Accordingly, we can rewrite $\int_{\underline{x}}^{\bar{x}} z(x) g\left(x \mid s^{S B}(t)\right) d x$ as

$$
\begin{aligned}
& \int_{\underline{x}}^{\hat{x}} z(x) g\left(x \mid s^{\prime}\right) \frac{g\left(x \mid s^{S B}(t)\right)}{g\left(x \mid s^{\prime}\right)} d x+\int_{\hat{x}}^{\bar{x}} z(x) g\left(x \mid s^{\prime}\right) \frac{g\left(x \mid s^{S B}(t)\right)}{g\left(x \mid s^{\prime}\right)} d x \\
> & \frac{g\left(\hat{x} \mid s^{S B}(t)\right)}{g\left(\hat{x} \mid s^{\prime}\right)}\left[\int_{\underline{x}}^{\bar{x}} z(x) g\left(x \mid s^{\prime}\right) d x\right]=0,
\end{aligned}
$$

where the last equality follows from the definition of $s^{\prime}$.

Since $\int_{\underline{x}}^{\bar{x}} z(x) g\left(x \mid s^{S B}(t)\right) d x>0$ and $\int_{\underline{x}}^{\bar{x}} t(x) g\left(x \mid s^{S B}(t)\right) d x=k$ by the definition of $s^{S B}(t)$ we have that $\int_{\underline{x}}^{\bar{x}} \tilde{t}(x) g\left(x \mid s^{S B}(t)\right) d x>k$. In words, the lender's conditional expected payoff at $s=s^{S B}(t)$ under $\tilde{t}$ is strictly greater than under $t$. As the conditional expected payoff under $t$ at $s=s^{S B}(t)$ is equal to $k$ by definition, this implies that the cutoff signal implemented by $\tilde{t}$ must be lower than that implemented by $t$, i.e., $s^{S B}(\tilde{t})<s^{S B}(t)$. To wrap up, we have found a debt contract $\tilde{t}$ that - if the acceptance region was $s>s^{S B}(t)$-yields both the lender and borrower the same expected payoff as the non-debt contract $t$. However, under $\tilde{t}$ the borrower is additionally accepted for lower signals $s \in\left(s^{S B}(\tilde{t}), s^{S B}(t)\right]$. Consequently, the lender is strictly better off under $\tilde{t}$ while the borrower's participation constraint is satisfied. (In fact, switching from $t$ to $\tilde{t}$ relaxes the borrower's participation constraint as it increases the probability of getting accepted.) This proves that an optimal contract must be debt.

Having established that the optimal contract is debt, uniqueness is straightforward. As the borrower's expected payoff is continuous in $R$ there exists for each $\bar{V}$ a compact set of $R$-values for which the borrower's participation constraint binds. As the lender's expected payoff is strictly increasing in $R$ the largest value of this set uniquely defines the optimal debt contract. Q.E.D.

Debt is optimal as it implements a lower cutoff signal than any other security. The argument in the proof also points to an easy-to-make mistake when thinking about possible alternative solution candidates (other than debt). It is easy to construct schemes that-holding the cutoff signal fixed-yield both the lender and the borrower the same expected payoff as the optimal debt contract. The premature conclusion is then that debt is not uniquely optimal. What is wrong with this argument is that any such scheme will implement a strictly higher cutoff signal than debt. (This is exactly what the above proof shows.) Hence the thought exercise of "holding 
the cutoff signal fixed" is illegitimate.

A good example is the "solution" of paying the borrower a fixed amount $K$ conditional upon acceptance and getting 100 per cent of the cash flow in return. That is, if the project is accepted the lender's payoff function is $x-K$, where the lump-sum $K$ is meant to provide the borrower with $\bar{V}$ in expectation. It is easy to set $K$ such that - if the implemented cutoff signal is the same as under the optimal debt contract - both the lender's and borrower's expected payoffs are the same as under the optimal debt contract. Can we conclude from this that this scheme does equally well as the optimal debt contract? No, the reason being that this scheme implements a strictly higher cutoff signal. The intuition, in this case, is particularly simple. Under a debt contract the borrower's participation constraint is satisfied by giving him cash flow only in high cash-flow states, hence leaving the lender with everything in low cash-flow states. This makes the lender less conservative. By contrast, under the above scheme a constant amount $K$ is given to the borrower in every cash-flow state. Hence the lender's payoff is $x-K$ for all $x$, which does not maximize her payoff in low cash-flow states.

Another "obvious" solution candidate is to give the lender a fraction $\delta \in[0,1]$ of the NPV. The idea is that if the lender obtains a fraction of the NPV she should maximize NPV and therefore implement the first-best credit policy. Precisely, the lender implements the first-best credit policy if and only if her conditional expected profit $\sum_{\theta \in \Theta} U_{\theta}(t) h(\theta \mid s)-k$ is zero if the NPV is zero, positive if the NPV is positive, and negative if the NPV is negative. By the definition of $s^{F B},(2)$, the NPV is zero at $s=s^{F B}$. Accordingly, the lender implements the first-best credit policy only if $\sum_{\theta \in \Theta} U_{\theta}(t) h\left(\theta \mid s^{F B}\right)=k$. Comparing (2) and (3) shows that this is true if and only if $\mu(\theta)=U_{\theta}(t)$ for all $\theta$, or equivalently, if and only if $t(x)=x$ for all $x$. In short, since the lender must contribute the full investment $\operatorname{cost} k$ the only way to give her a fraction of the NPV for all $s \in[0,1]$ —including $s=s^{F B}$ —is to give her the entire cash flow, i.e., $\delta=1$.

The lender's expected payoff is strictly increasing in the repayment level $R$. As a decrease in $\bar{V}$ relaxes the borrower's participation constraint, optimality implies that the lender raises $R$. From the equation characterizing the second-best credit policy, (3), it then follows that the lender can lower the cutoff signal $s^{S B} \cdot{ }^{17}$ This is summarized in the following corollary. Given

\footnotetext{
${ }^{17}$ Incidentally, the borrower's expected payoff is not monotonic in $R$. While an increase in $R$ has a negative direct effect, it has a positive indirect effect in that it lowers the cutoff signal $s^{S B}$, thereby increasing the probability of acceptance. Neither of these two effects is dominant. For instance, if $R=\bar{x}$ the borrower's expected payoff is
} 
the preceding results the proof is obvious.

Corollary 1. An increase in $\bar{V}$ reduces the optimal repayment level $R$ and raises the second-best cutoff signal $s^{S B}$, thereby increasing the wedge between the first- and second-best credit policy.

The effect of an increase in $\bar{V}$ on the cutoff signal can be easily seen from Figure 1 for the case where $t$ is the optimal contract. An increase $\bar{V}$, implying a decrease in $R$, does not affect the conditional expected cash flow $a(s)$. It does, however, reduce the lender's expected payoff from a type- $\theta$ borrower, $U_{\theta}(t)$, and thus her conditional expected payoff under the optimal contract, $b(s)$. Accordingly, an increase in $\bar{V}$ - while having no effect on $a(s)$ - pushes $b(s)$ down, thereby increasing the wedge between the first- and second-best cutoff signals $s^{F B}$ and $s^{S B}$.

If $\bar{V}$ is driven by credit market competition (Section 4.7), Corollary 1 has the following implication: Following an increase in competition lenders become more conservative and reject any given borrower with a higher probability. Several studies document a negative relation between credit availability for small firms and credit market competition, e.g., Petersen and Rajan (1994) and Cetorelli and Gambera (2001). These studies also find that the adverse effect of competition is strongest for firms that are young, small, and relatively opaque. In other words, firms for which there is considerable quality uncertainty. This is precisely the type of situation in which credit risk analysis is most valuable.

\subsection{Models of Debt}

This paper provides a new, and intuitive argument for debt based on the notion that the incentives of lenders to accept or reject loan applicants depend on the security in place. While the lender will generally be too conservative debt minimizes this inefficiency. Let us briefly point out the main differences between our argument and other arguments for debt. Evidently, our model is different from costly state-verification models (Townsend (1979), Gale and Hellwig (1985), and repeated lending models with non-verifiable cash flow (Bolton and Scharfstein (1990), Hart and Moore (1998), DeMarzo and Fishman (2000), Inderst and Müller (2002a)). Also, risk-sharing considerations (as in, e.g., Allen and Gale (1988)) play no role here.

Nachman and Noe (1994), DeMarzo and Duffie (1999), and Biais and Mariotti (2001) consider

zero. If $R=0$, however, the cutoff signal is $s^{S B}=1$ (the lender cannot possibly break even), and the borrower's expected payoff is also zero. All we need for the argument that $R$ is strictly increasing in $\bar{V}$, however, is that the borrower's expected payoff is continuous in $R$. 
private information on the part of the borrower either before or after the security design. While our model can be extended to incorporate such private information (see Section 4.5), private information is not important, or necessary, for our results. To underscore this point we assume that the borrower and lender have common priors.

More fundamentally — and going back to Myers and Majluf (1984) — the idea in private information models is that debt minimizes the underpricing as it is relatively information insensitive to the borrower's private information. If possible, the borrower would like to issue riskless debt, thereby fully eliminating the lemons problem. ${ }^{18}$ By contrast, in our model the problem is to trade off type- 1 and type- 2 errors. In Section 3.1 we showed that the first-best credit policy is implementable if and only if $t(x)=x$, i.e., if and only if the lender gets the entire cash flow. Hence the idea is not to shield the lender from cash-flow risk but - on the contrary - to expose her to sufficient risk so that she has the right incentives to trade off the two types of errors. Specifically, as the lender is always too conservative the optimal security induces her to lower the cutoff signal, much like the optimal contract in a moral hazard model induces the agent to work hard.

In Innes' (1990) moral hazard model the optimal security design also solves an incentive problem. In his model the incentive problem is with the borrower (i.e., the entrepreneur), while in our model it is with the lender. Moreover, there is no analogue of our (endogenously) optimal cutoff rule - or accept/reject decision. There is another, fundamental difference between the two incentive problems, however. For simplicity suppose there are two effort levels, $\theta=1,2$. Denote the agent's utility (including effort cost) under the contract $t$ by $U_{\theta}(t)$. In Innes' model the agent's incentives depend only on the utility difference $U_{2}(t)-U_{1}(t)$. Accordingly, a nonmonotonic contract generating the same utility difference as 100 per cent equity can often attain the first best (Innes (1990), Section 4). By contrast, in our model the lender's incentives depend both on the utility difference $U_{2}(t)-U_{1}(t)$ and on the absolute levels $U_{1}(t)$ and $U_{2}(t)$. In particular, if $U_{1}(t)$ and $U_{2}(t)$ do not assume their first-best values (i.e., if the lender does not get the full NPV) the first-best outcome cannot be attained - regardless of what value the utility difference $U_{2}(t)-U_{1}(t)$ takes. Put differently, incentives in our model depend on absolute expected cash flows, while in Innes' model they depend on marginal expected cash flows.

\footnotetext{
${ }^{18}$ Riskless debt may have other disadvantages, however. For instance, issuing riskless debt forces the issuer to retain a potentially large fraction of the project cash flow (DeMarzo and Duffie (1999), Axelson (2002)).
} 


\section{General Discussion}

\subsection{Menu of Contracts}

While the contract cannot directly condition on $s$ there remains the possibility that the lender chooses a contract from a prespecified menu after observing $s$, hence potentially revealing the signal. We now investigate this possibility formally. By standard arguments we can restrict attention to mechanisms of the following kind. The lender offers a menu of contracts. After observing the signal the lender can reject or accept the applicant. If the applicant is accepted the lender is free to choose any contract from the menu. ${ }^{19} \mathrm{~A}$ menu is a collection $\left(t_{i}\right)_{i \in I}$ of contracts, where $I$ is an index set and each contract in the menu is ex-post optimal for the lender for some $s \in S$ given the other contracts in the menu.

In the Appendix we show that the unique optimal menu consists of a single contract. The argument - in a nutshell - is that with a menu available the lender will always choose the contract that is ex-post optimal for her. But if she extracts more surplus from the borrower at inframarginal signals $s>s^{S B}$ she must leave the borrower more surplus at the marginal signal $s^{S B}$. This raises the cutoff signal $s^{S B}$ at which the lender breaks even. Hence by committing to a single contract the lender commits to a lower cutoff signal. ${ }^{20}$

A lengthier, but more detailed intuition goes as follows. If $\bar{V}=0$ the optimal contract is $t(x)=x$ and there is no tension between ex-ante and ex-post optimality. Suppose therefore that $\bar{V}>0$. Clearly, the menu cannot contain $t(x)=x$, for then the lender would always select this contract, implying that the borrower's expected payoff is zero. But if $t(x)=x$ is not in the menu our previous logic applies by which the lowest acceptable signal is $s^{S B}>s^{F B}$. The optimal menu thus (again) minimizes the efficiency loss from excessive rejection. Suppose now that upon observing $s^{S B}$ the lender chooses the contract $t^{S B}$, while for higher signals $s>s^{S B}$ different contracts $t_{i} \neq t^{S B}$ are chosen. If we delete all contracts $t_{i} \neq t^{S B}$ from the menuthereby committing the lender to choosing $t^{S B}$ - it follows from revealed preference that the lender's expected payoff decreases and the borrower's expected payoff increases (viz., above $\bar{V}$ ).

\footnotetext{
${ }^{19}$ This setting follows Maskin and Tirole (1990, 1992).

${ }^{20}$ We assume that such commitment is possible. The assumption can be made explicit by adding to the original contract (or menu) a clause saying that if the lender ever agrees to a different contract she will have to pay a large fine. In practice, reputation and cost concerns prevent banks from deviating from standardized loan packages. This is particularly true in the retail market where profit margins are small. (See Saunders and Thomas (2001)).
} 
This, in turn, allows the lender to alter the terms of the remaining contract $t^{S B}$ in a way that increases her expected payoff without violating the borrower's participation constraint. By our previous arguments this lowers the cutoff signal, which implies the original menu cannot be optimal, contradiction. The following proposition is proven in the Appendix.

Proposition 2. The unique optimal menu consists of a single contract. That is, it is optimal for the lender to offer a single contract that is either given or not given. Any nondegenerate menu-while containing contracts that the lender might prefer ex post-implements a strictly higher cutoff signal and is thus suboptimal for the lender from an ex-ante viewpoint.

\subsection{Ordering of Signal-Generating Distributions}

Assumption 2 requires that the signal-generating distribution $F_{\theta}(s)$ satisfies MLRP. In conjunction with Assumption 1 this implies that the conditional cash-flow distribution $G(x \mid s)$ also satisfies MLRP. (See footnote 8.) In this and the following sections we show that MLRP of $G(x \mid s)$ is not necessary for our results. ${ }^{21}$

In this section we relax Assumption 2. We replace it by the following set of assumptions.

Assumption 2a. The hazard rate $f_{\theta}(s) /\left[1-F_{\theta}(s)\right]$ is strictly decreasing in $\theta$ for all $s<1$.

Assumption 2a is equivalent to requiring that for any pair $\left(\theta, \theta^{\prime}\right) \in \Theta$ with $\theta^{\prime}>\theta$ the ratio $\left[1-F_{\theta^{\prime}}(s)\right] /\left[1-F_{\theta}(s)\right]$ is strictly increasing in $s$ for all $s<1$. Nachman and Noe (1994) refer to this condition as Conditional Stochastic Dominance. It has the natural interpretation that the relative likelihood of a high type exceeding a particular cutoff signal (as opposed to a low type exceeding it) is increasing in the cutoff signal. Put simply, higher cutoff signals do a better job at filtering out high types.

Assumption 2b. The posterior distribution $H(\theta \mid s)$ satisfies strict FOSD.

It is easily established that Assumption 2 implies both Assumptions 2a and 2b, but not vice versa. In particular, Assumptions $2 \mathrm{a}$ and $2 \mathrm{~b}$ do not imply that the conditional cash-flow distribution $G(x \mid s)$ satisfies MLRP.

Assumption 1 in conjunction with Assumption 2b ensures that the conditional expected payoff from any nondecreasing function $t(x)$ is strictly increasing in $s$. Both the first- and

\footnotetext{
${ }^{21}$ It does, however, considerably simplify the proof that debt is the unique optimal security. Simplicity of the proof - and thus transparancy of our main result - is what guided us in favoring Assumptions 1 and 2 over the weaker assumptions discussed in this and the following section.
} 
second-best credit policies thus follow again simple cutoff rules (Lemmas 1 and 2). Moreover, as we pointed out earlier the inefficiency result in Lemma 3 does not depend on Assumption 2 and is therefore unaffected by the change in assumptions. Most importantly, however, debt remains the unique optimal security. The following result is proven in the Appendix.

Proposition 3. If Assumption 2 is replaced by Assumptions 2a and 2b Proposition 1 continues to hold, i.e., debt remains the unique optimal security.

\subsection{Ordering of Cash-Flow Distributions}

On top of relaxing Assumption 2 we now also relax Assumption 1, albeit at the cost of strenghtening Assumption 3. Consider the following weaker assumption regarding $G_{\theta}(x)$.

Assumption 1a. The hazard rate $g_{\theta}(x) /\left[1-G_{\theta}(x)\right]$ is strictly decreasing in $\theta$ for all $x<\bar{x}$.

As in the case of Assumption 2a there exists an equivalent representation in terms of the ratio $\left[1-G_{\theta^{\prime}}(x)\right] /\left[1-G_{\theta}(x)\right]$. We next strengthen Assumption 3 by requiring that in addition to $t(x)$ being nondecreasing the borrower's ex-post profit $x-t(x)$ be nondecreasing in $x$. The usual argument for this in the contracting literature is that if $x-t(x)$ were decreasing the borrower could make an arbitrage gain by destroying cash flow ex post.

Assumption 3a. $t(x)$ and $x-t(x)$ are both nondecreasing.

By our previous arguments it is immediate that Lemmas 1-3 continue to hold under this new set of assumptions. The same is true for our main result that debt is the unique optimal security. The proof of the following proposition is in the Appendix.

Proposition 4. If Assumptions 1-3 are replaced by Assumptions 1a, 2a-b, and 3a, Proposition 1 continues to hold, i.e., debt remains the unique optimal security.

\subsection{Variable Investment Size}

Suppose it is possible to carry out a miniature version of the project where both $k$ and $x$ are multiplied by a factor $\gamma \leq 1$. Scaling down the project has costs. If the project is accepted its conditional expected NPV is $\gamma\left[\sum_{\theta \in \Theta} h(\theta \mid s) \mu(\theta)-k\right]$, which is only a fraction of the full NPV. The potential benefit - one might think - is that reducing the lender's investment makes her less cautious, thus improving the (second-best) optimal credit policy. In what follows we show that this is not true. Specifically, we show that the second-best cutoff signal associated 
with a scaled-down project is higher than or equal to the second-best cutoff signal associated with the full project. ${ }^{22}$ In conjunction with the fact that scaling down means foregoing positive NPV opportunities this implies that scaling down is not optimal.

A contract now prescribes a scaling factor $0<\gamma \leq 1$ and a repayment scheme $t(x) \leq \gamma x$. The cutoff signal $s^{S B}(\gamma, t)$ is determined by the usual break-even condition

$$
\sum_{\theta \in \Theta} h\left(\theta \mid s^{S B}(\gamma, t)\right) U_{\theta}(t)=\gamma k
$$

To show that scaling down is not optimal we argue to a contradiction, assuming that some contract $(\gamma, t)$ with $\gamma<1$ is optimal. Consider a new contract $(1, \tilde{t})$ with $\tilde{t}(x)=(1-\gamma) x+t(x)$. Under the new contract the project is carried out in its entirety. Moreover, the additional cash flow $(1-\gamma) x$ coming from the increase $\gamma$ from $\gamma<1$ to $\gamma=1$ accrues to the lender. The lender's conditional expected payoff minus the investment cost ("conditional expected profit") under the new contract $(1, \tilde{t})$ given the "old" cutoff signal $s^{S B}(\gamma, t)$ is

$$
\begin{aligned}
\sum_{\theta \in \Theta} h\left(\theta \mid s^{S B}(\gamma, t)\right) U_{\theta}(\tilde{t})-k & =\sum_{\theta \in \Theta} h\left(\theta \mid s^{S B}(\gamma, t)\right) U_{\theta}(t)+\sum_{\theta \in \Theta} h\left(\theta \mid s^{S B}(\gamma, t)\right)(1-\gamma) \mu(\theta)-k \\
& =(1-\gamma)\left[\sum_{\theta \in \Theta} h\left(\theta \mid s^{S B}(\gamma, t)\right) \mu(\theta)-k\right]
\end{aligned}
$$

where the last equality is obtained by inserting (6). The fact that $\gamma<1$-in conjunction with the fact that $\sum_{\theta \in \Theta} h(\theta \mid s) \mu(\theta)$ is increasing in $s$ and that $s^{S B}(\gamma, t) \geq s^{F B}$-implies that the term in the second row is either zero (if $s^{S B}(\gamma, t)=s^{F B}$ ) or positive (if $s^{S B}(\gamma, t)>s^{F B}$, since $\sum_{\theta \in \Theta} h(\theta \mid s) \mu(\theta)$ is increasing in $\left.s\right)$. If the second row is zero we have that $s^{S B}(1, \tilde{t})=$ $s^{S B}(\gamma, t)=s^{F B}$, implying that $\bar{V}=0, t(x)=\gamma x$ and $\tilde{t}(x)=x$. By contrast, if the second row is positive the left-hand side in (7) must also be positive. In this case the lender's conditional expected payoff at $s=s^{S B}(\gamma, t)$ under $(1, \tilde{t})$ is strictly greater than $k$, implying that the cutoff signal implemented by $(1, \tilde{t}), s^{S B}(1, \tilde{t})$, is strictly lower than $s^{S B}(\gamma, t)$. Switching from $(\gamma, t)$ to $(1, \tilde{t})$ therefore increases the probability of acceptance. Given that the borrower's payoff conditional upon acceptance is the same under $t$ and $\tilde{t}$ by construction, switching from $(\gamma, t)$ to $(1, \tilde{t})$ makes both the lender and borrower better off, contradicting the optimality of $(\gamma, t)$. Hence scaling down the project either leaves the lender's credit policy unchanged (if $\bar{V}=0$ )

\footnotetext{
${ }^{22}$ As both the left- and right-hand side in (2) are multiplied by $\gamma$ the first-best cutoff signal $s^{F B}$ is independent of $\gamma$. Hence the benchmark against which the lender's credit policy is evaluated remains unchanged.
} 
or worsens it (if $\bar{V}>0$ ). In conjunction with the fact that it reduces the NPV of an accepted project this implies that scaling down is never optimal.

Proposition 5. Scaling down the investment project is not optimal.

\subsection{Fully Revealing Signal}

None of our results depend on the signal being a noisy predictor of the borrower's type. Consider the following simple relabeling of our model. There is a continuum of types $s \in S$. Each type respresents a portfolio consisting of all possible projects $\theta \in \Theta$ with type-dependent portfolio weights $h(\theta \mid s)$. Upon observing the signal $s$ the lender now knows exactly the borrower's type. And yet, the fundamental uncertainty about cash flows is the same as before since a type now represents a weighted average of cash-flow distributions.

It is straightforward to show that - once we introduce the necessary changes in notationall our results obtain. The cutoff signal then becomes a "cutoff type" representing the lowest acceptable type.

\subsection{Private Information about Project Quality}

Debt remains the unique optimal security if the borrower has private information about the project quality. The argument is as follows. If the borrower and lender have common priors the borrower's participation constraint needs to be met only in expectation (ex-ante participation constraint). If the borrower has private information about his type, however, the participation constraint must be satisfied for every single type the lender wants to attract (interim participation constraint), while reservation utilities will be type-dependent.

If the lender wants to attract only high-type borrowers (as in our model) the optimal security design has two objectives: (i) minimizing the efficiency loss from excessive rejection, and (ii) minimizing the rent extracted by low-type borrowers (while satisfying the participation constraint of high-type borrowers). Objective (ii) is equivalent to minimizing the mispricing. As for objective (i) we have shown that a debt contract maximizes the lender's payoff from low-type borrowers, thereby making her less conservative. But this is the same as saying that debt minimizes the rent extracted by low-type borrowers. Hence a debt contract satisfies both objectives (i) and (ii), implying that it remains optimal if borrowers have private information. ${ }^{23}$

\footnotetext{
${ }^{23}$ See Myers and Majluf (1984) and Nachman and Noe (1994) for details. The assumptions in our model and
} 


\subsection{Credit Market Competition}

The extent to which the credit decision is (in-)efficient depends on the variable $\bar{V}$, which reflects the borrower's ability to capture a share of the surplus. If $\bar{V}=0$ the credit decision is first-best efficient while if $\bar{V}>0$ it is inefficient. We argued earlier that if the borrower and lender were to bargain over a contract $\bar{V}>0$ would be the natural outcome even in a monopoly. Another reason for why the borrower might capture a share of the surplus is credit market competition. Generally, the notion is that competition will drive up $\bar{V}$, thereby increasing the wedge between the first- and second-best cutoff signals (Lemma 3).

One potential setting we have in mind is that of a small business seeking credit from its local bank. The local bank may have an advantage over other lenders due to its familiarity with local conditions, superior knowledge of the firm, or simply greater proximity. Sharpe (1990), Rajan (1992), and von Thadden (1995) model the informational advantage of banks arising from credit relationships, while in Boot and Thakor (2000) banks can specialize to become relationship lenders. ${ }^{24}$ As in our model, the relative advantage of the local bank creates a wedge between the borrower's utility if he is accepted and his utility if he is rejected, which is what we need for our results. As we argued earlier, however, this is only one of many reasons why the credit market might exhibit frictions, suggesting that competition is imperfect. Other reasons are search costs and disclosure risk (see Section 2.3).

The advantage of the local bank also implies that only borrowers who are rejected will seek finance from another bank. E.g., Petersen and Rajan (1994) argue that "[l]ower quality firms, unable to borrow additional money from their first bank, must approach other banks for additional capital. If so, the unwillingness of the original bank to extend the firm additional credit may be a signal of the firm's riskiness or quality, and the firm can obtain credit at a second bank only at a higher rate." Similarly, Mizruchi and Stearns (1993) argue that once a relation between borrower and lender has been established the borrower's freedom to shop for cheaper sources of capital is constrained.

\footnotetext{
Nachman and Noe's model do not conflict.

${ }^{24}$ The notion that small firms borrow primarily from a single local bank is borne out in the data. In Petersen and Rajan (1994) 76 percent of the largest, but 95 percent of the smallest firms in their sample obtain their loans from a single bank. Overall, only 18 percent borrow from more than one bank. While the distance between banks and their borrowers has increased over the years the median distance is still only five miles, suggesting that local banks have an advantage over more distant lenders (Petersen and Rajan (2002)).
} 
While alternative sources of funding (trade credit, other banks) may be more costly their presence nevertheless puts a lower bound on the surplus that the local bank must leave its borrowers. Specifically, as alternative sources of funding become relatively more attractive $\bar{V}$ will increase. While an increase in $\bar{V}$ implies that the bank must grant its borrowers more surplus, there is no good reason why this should be done inefficiently. In the paper we show that there is a unique efficient way of satisfying the borrower's participation constraint, viz., to offer a debt contract and adjust the repayment level, if necessary. This is true for all feasible values of $\bar{V}$. To the extent that credit market competition drives up $\bar{V}$ the results in this paper thus extend to all possible competition levels. ${ }^{25}$

\section{Concluding Remarks}

Credit decisions are almost inevitably subjective even if based on "hard" information such as financial statements. We consider a simple lending model where the lender analyzes the borrower's credit risk prior to making the credit decision. Based on the outcome of the analysis the lender either accepts or rejects the borrower, implying that the credit decision is fully discretionary. We show that regardless of the contract in place the lender is too conservative in the sense that she uses a hurdle rate that is higher than first-best optimal. Given that the lender's incentives to accept or reject depend on the contract we next ask what contract minimizes the efficiency loss from excessive rejection. (This is also the contract that maximizes the lender's profit subject to the borrower's participation constraint.) We show that the unique optimal contract is a standard debt contrat. Debt maximizes the lender's payoff in low cash-flow states, thereby maximizing her return from low-type borrowers, i.e., borrowers with a high probability mass on low cash-flow outcomes. Having less to loose from financing a low-type project the lender becomes less conservative. Consequently, the hurdle rate implemented by a debt contract is lower than under any other security, and thus closest to the first-best value.

Unlike most models of security design the incentive problem in our model is with the lender-

\footnotetext{
${ }^{25} \mathrm{~A}$ formal model along the lines sketched in this section is beyond the scope of this paper. As shown in Broecker (1990) and von Thadden (1998), if lenders compete under asymmetric information-e.g., because they cannot distinguish between a "fresh" applicant and someone who has been rejected by another lender-there exists no equilibrium in pure strategies. The reason is a "pool externality" arising from the fact that rejecting an applicant worsens the pool of potential applicants for other lenders.
} 
not with the borrower. Specifically, the security in place determines the lender's incentives to accept or reject loan applicants. In the paper we argue that the optimality of debt is robust with respect to introducing private information on the part of the borrower. Furthermore, it is plausible that debt remains optimal if we introduce ex-post moral hazard on the part of the borrower. (See Innes (1990); our assumptions and his assumptions do not conflict.) The outcome is less clear if - in addition to the ex-ante incentive problem considered here - there is ex-post moral hazard both on the part of the borrower and on the part of the lender. Such double-sided moral hazard is frequently assumed in models of venture capital contracting. There, the conclusion is usually that some equity-linked security such as convertible debt is optimal. Exploring the tension between double-sided ex-post moral hazard (which appears to favor equitylinked securities) and ex-ante lender moral hazard (which appears to favor debt) in the same model is an interesting avenue for future research.

\section{Appendix}

Proof of Proposition 2. By Assumptions 1-3 the lender's optimal credit policy involves a unique cutoff signal - even if a menu is offered. (See Lemma 2.) By the argument in the main text we then have that $s^{S B}>s^{F B}$ if and only if $\bar{V}>0$. The optimal menu minimizes the efficiency loss from excessive rejection. In a slight deviation from what we specified in Section 3.1 we now assume that in case of indifference the lender accepts. This allows us to determine a contract $t^{S B}$ that is implemented at the lowest acceptable signal $s=s^{S B} \cdot{ }^{26}$ As $s=s^{S B}$ is a zero-probability event this change in assumptions is without consequences.

Suppose a menu $T=\left\{t_{i}\right\}_{i \in I}$ is offered from which the lender selects contracts other than $t^{S B}$ with positive probability. We show that such a menu is not optimal. Consider the degenerate menu $T^{\prime}:=\left\{t^{S B}\right\}$, which is constructed from $T$ by deleting all contracts but $t^{S B}$. Note that $T^{\prime}$ implements the same cutoff signal as $T$. As the deletion restricts the lender's choice for higher signals $s \geq s^{S B}$ the borrower cannot be worse off. We now distinguish between the two cases: one where $t^{S B}$ is a debt contract and one where $t^{S B}$ is not a debt contract. Suppose first that $t^{S B}$ is not a debt contract. We can then construct a new degenerate menu $T^{\prime \prime}:=\left\{\tilde{t}^{S B}\right\}$ where the debt contract $\tilde{t}^{S B}$ is constructed from $t^{S B}$ as in the Proof of Proposition 1. By the same logic as in that proof the cutoff signal implemented by $T^{\prime \prime}$ is strictly lower than $s^{S B}$, which immediately

\footnotetext{
${ }^{26}$ In case of randomization $t^{S B}$ lies in the support of the lender's distribution if $s=s^{S B}$.
} 
implies that $T$ cannot be optimal. Suppose next that $t^{S B}$ is a debt contract. We show that by switching from $T$ to $T^{\prime}$ the borrower's participation constraint becomes slack. This follows immediately if the lender strictly prefers some contract $t_{i} \in T$ to $t^{S B}$ after observing $s>s^{S B}$. In what follows we show that this is indeed true if contracts other than $t^{S B}$ are implemented with positive probability. Precisely, we prove that if the lender is indifferent between $t^{S B}$ and some contract $\widehat{t} \neq t^{S B}$ at some signal $\widehat{s}<1$ he must strictly prefer $\widehat{t}$ to $t^{S B}$ at all higher signals $s>\widehat{s}$. This is implied by MLRP of $G(x \mid s)$. The proof uses an argument similar to that in the Proof of Proposition 1.

By the definition of $\widehat{t}$ we have $\int_{\underline{x}}^{\bar{x}} z(x) g(x \mid \widehat{s}) d x=0$, where $z(x):=t^{S B}(s)-\widehat{t}(x)$. Moreover, by Assumption 3 and since $t^{S B}$ is a debt contract there exists some $\hat{x} \in(\underline{x}, \bar{x})$ such that $z(x) \geq 0$ for all $x<\hat{x}$ and $z(x) \leq 0$ for all $x>\hat{x}$, where the inequalities are strict over sets of positive measure. Using MLRP of $G(x \mid s)$ we can then rewrite $\int_{\underline{x}}^{\bar{x}} z(x) g(x \mid s) d x$ for $s>\widehat{s}$ as

$$
\begin{aligned}
& \int_{\underline{x}}^{\hat{x}} z(x) g(x \mid \widehat{s}) \frac{g(x \mid s)}{g(x \mid \widehat{s})} d x+\int_{\hat{x}}^{\bar{x}} z(x) g(x \mid \widehat{s}) \frac{g(x \mid s)}{g(x \mid \widehat{s})} d x \\
< & \frac{g(\hat{x} \mid s)}{g(\hat{x} \mid \widehat{s})}\left[\int_{\underline{x}}^{\bar{x}} z(x) g(x \mid \widehat{s}) d x\right]=0 .
\end{aligned}
$$

This completes the proof of Proposition 2. Q.E.D.

Proof of Proposition 3. The proof is largely analogous to that of Proposition 1. We will thus be brief. To prove that debt is uniquely optimal if $\bar{V}>0$ we argue again to a contradiction. We assume that some contract $t$ that is not debt is optimal. We next construct a debt contract $\tilde{t}$ that would leave both the borrower's and lender's expected payoffs unchanged if the cutoff signal $s^{S B}(t)$ was used. In a slight abuse of the notation used in the Proof of Proposition 1 we define $z(\theta):=\int_{x \in X}[\tilde{t}(x)-t(x)] g_{\theta}(x) d x$. By the definition of $\tilde{t}$ we have

$$
\sum_{\theta \in \Theta} h(\theta)\left[1-F_{\theta}\left(s^{S B}(t)\right)\right] z(\theta)=0 .
$$

We now need to introduce some additional notation. If all that was known is that the signal is greater than some value $\hat{s}$ the probability the conditional distribution would put on type $\theta$ is

$$
\bar{h}(\theta \mid \hat{s}):=\frac{h(\theta)\left[1-F_{\theta}(\hat{s})\right]}{\sum_{\theta^{\prime} \in \Theta} h\left(\theta^{\prime}\right)\left[1-F_{\theta^{\prime}}(\hat{s})\right]} .
$$

With this definition at hand (8) transforms to

$$
\sum_{\theta \in \Theta} z(\theta) \bar{h}\left(\theta \mid s^{S B}(t)\right)=0
$$


Claim 1. There exists a type $\tilde{\theta} \in \Theta$ with $1 \leq \tilde{\theta}<\bar{\theta}$, such that the following holds:

i) If $\bar{\theta}>2$ it holds that $\tilde{\theta}>1, z(\tilde{\theta}) \geq 0$, and $z(\theta)>0$ for all $\theta<\tilde{\theta}$. If $\bar{\theta}=2$ it holds that $z(\tilde{\theta})>0$ with $\tilde{\theta}=1$.

ii) For all $\theta>\tilde{\theta}$ it holds that $z(\theta)<0$.

Proof. By the construction of $\tilde{t}$ and $z(\theta)$ there must exist types for which $z(\theta)<0$ and types for which $z(\theta)>0$. Moreover, by Assumption 3 and the construction of $\tilde{t}$ there exists a value $\tilde{x}$ in the interior of $X$ such that $\tilde{t}(x) \geq t(x)$ for $x<\tilde{x}$ and $\tilde{t}(x) \leq t(x)$ for $x>\tilde{x}$, where the inequalities hold strictly over sets of positive measure. Given some pair $\theta^{\prime}>\theta$ in $\Theta$ we can now transform $z\left(\theta^{\prime}\right)$ to

$$
z\left(\theta^{\prime}\right)=\int_{\underline{x}}^{\tilde{x}}[\tilde{t}(x)-t(x)] g_{\theta}(x) \frac{g_{\theta^{\prime}}(x)}{g_{\theta}(x)} d x+\int_{\tilde{x}}^{\bar{x}}[\tilde{t}(x)-t(x)] g_{\theta}(x) \frac{g_{\theta^{\prime}}(x)}{g_{\theta}(x)} d x .
$$

As $g_{\theta^{\prime}}(x) / g_{\theta}(x)$ is strictly increasing in $x$ by Assumption 1 the construction of $\tilde{x}$ implies

$$
z\left(\theta^{\prime}\right)<\frac{g_{\theta^{\prime}}(\tilde{x})}{g_{\theta}(\tilde{x})} z(\theta)
$$

From (10) it follows that $z(\theta) \leq 0$ implies $z\left(\theta^{\prime}\right)<0$ for all higher types $\theta^{\prime}>\theta$. This proves the existence of a type $\tilde{\theta}$ with the asserted properties Q.E.D.

Claim 2. $\sum_{\theta \in \Theta} z(\theta) h\left(\theta \mid s^{S B}(t)\right)>0$.

Proof. Using (9) and the definitions of $h\left(\theta \mid s^{S B}(t)\right)$ and $\bar{h}\left(\theta \mid s^{S B}(t)\right)$, we obtain

$$
\begin{aligned}
& \sum_{\theta \in \Theta} z(\theta) h\left(\theta \mid s^{S B}(t)\right) \\
= & \sum_{\theta \in \Theta} z(\theta) h\left(\theta \mid s^{S B}\right) \frac{\bar{h}\left(\theta \mid s^{S B}(t)\right)}{\bar{h}\left(\theta \mid s^{S B}(t)\right)} \\
= & \sum_{\theta \in \Theta} z(\theta) \bar{h}\left(\theta \mid s^{S B}(t)\right)\left[\frac{f_{\theta}\left(s^{S B}(t)\right)}{1-F_{\theta}\left(s^{S B}(t)\right)}\right]\left[\frac{\sum_{\theta^{\prime} \in \Theta} h\left(\theta^{\prime}\right)\left(1-F_{\theta^{\prime}}\left(s^{S B}(t)\right)\right)}{\sum_{\theta^{\prime} \in \Theta} h\left(\theta^{\prime}\right) f_{\theta^{\prime}}\left(s^{S B}(t)\right)}\right] .
\end{aligned}
$$

Define $\alpha(\theta):=f_{\theta}\left(s^{S B}(t)\right) /\left[1-F_{\theta}\left(s^{S B}(t)\right)\right]$. Moreover, abbreviate the term in the rightmost bracket by $\beta$. By Assumption 2a we have that $\alpha$ is strictly decreasing. Using (9) then yields

$$
\begin{aligned}
\sum_{\theta \in \Theta} z(\theta) h\left(\theta \mid s^{S B}(t)\right) & =\beta\left[\sum_{\theta \leq \tilde{\theta}} \alpha(\theta) z(\theta) \bar{h}\left(\theta \mid s^{S B}(t)\right)+\sum_{\theta>\tilde{\theta}} \alpha(\theta) z(\theta) \bar{h}\left(\theta \mid s^{S B}(t)\right)\right] \\
& >\alpha(\tilde{\theta}) \sum_{\theta \in \Theta} z(\theta) \bar{h}\left(\theta \mid s^{S B}(t)\right)=0 .
\end{aligned}
$$

\section{Q.E.D.}


Given Claim 2 - and similar to the Proof of Proposition 1 - we can conclude that $s^{S B}(t)>$ $s^{S B}(\tilde{t})$, which proves that the nondebt contract $t$ cannot be optimal. The rest is identical to the Proof of Proposition 1. Q.E.D.

Proof of Proposition 4. The proof is analogous to that of Proposition 3. The only difference is in the proof of Claim 1, where we previously used the stronger Assumption 1. We thus restrict ourselves to showing that Claim 1 continues to hold under Assumptions 1a and 3a.

By Assumption 3a $t(x)$ is continuous, nondecreasing, and satisfies $t\left(x^{\prime}\right)-t(x) \leq x^{\prime}-x$ for all $x, x^{\prime} \in X$. By monotonicity it is also differentiable almost everywhere. The derivative, where it exists, is denoted by $d(x)$. Partial integration then yields

$$
\int_{\underline{x}}^{\bar{x}} t(x) d G_{\theta}(x)=t(\underline{x})+\int_{\underline{x}}^{\bar{x}} d(x)\left[1-G_{\theta}(x)\right] d x .
$$

Denote the repayment level associated with the debt contract $\tilde{t}$ by $\underline{x}<\tilde{x}<\bar{x}$. By the definition of $\tilde{t}$ the derivative equals one if $x<\tilde{x}$ and zero if $x>\tilde{x}$. Using the definition of $z(\theta)$ and (11), we obtain

$$
z(\theta)=[\underline{x}-t(\underline{x})]+\int_{\underline{x}}^{\tilde{x}}[1-d(x)]\left[1-G_{\theta}(x)\right] d x-\int_{\tilde{x}}^{\bar{x}} d(x)\left[1-G_{\theta}(x)\right] d x
$$

For any two types $\theta^{\prime}>\theta$ in $\Theta$, we can transform $z\left(\theta^{\prime}\right)$ to

$$
\begin{aligned}
z\left(\theta^{\prime}\right)= & \underline{x}-t(\underline{x})+\int_{\underline{x}}^{\tilde{x}}[1-d(x)]\left[1-G_{\theta}(x)\right]\left[\frac{1-G_{\theta^{\prime}}(x)}{1-G_{\theta}(x)}\right] d x \\
& -\int_{\tilde{x}}^{\bar{x}} d(x)\left[1-G_{\theta}(x)\right]\left[\frac{1-G_{\theta^{\prime}}(x)}{1-G_{\theta}(x)}\right] d x .
\end{aligned}
$$

Next observe that $0 \leq d(x) \leq 1$ by Assumption 3a. Moreover, by construction of $\tilde{t}$ it follows that $d(x)>0$ holds strictly on a set of positive measure for $x>\tilde{x}$, while either $d(x)<1$ holds strictly on a set of positive measure for $x<\tilde{x}$ or it holds that $t(\underline{x})<\underline{x}$. Together with Assumption 1a we then obtain

$$
z\left(\theta^{\prime}\right)<\frac{1-G_{\theta^{\prime}}(\tilde{x})}{1-G_{\theta}(\tilde{x})} z(\theta)
$$

which is equivalent to (10) in Claim 1 of the Proof of Proposition 1. Q.E.D.

\section{References}

Allen, F., and Gale, D., 1988, Optimal security design, Review of Financial Studies 1, 229-263. 
Allen, F., and Winton, A., 1995, Corporate financial structure, incentives and optimal contracting, in: Handbooks in Operations Research and Management Science, Vol.9: Finance, R. Jarrow, V. Maksimovic, and W.T. Ziemba, eds., Amsterdam: North-Holland.

Berlin, M., John, K., and Saunders, A., 1996, Bank equity stakes in borrowing firms and financial distress, Review of Financial Studies 9, 889-919.

Biais, B., and Mariotti, T., 2001, Strategic liquidity supply and security design, mimeo, University of Toulouse.

Binmore, K., Rubinstein, A. and Wolinsky, A., 1986, The Nash bargaining solution in economic modelling, Rand Journal of Economics 17, 176-255.

Bolton, P., and Scharfstein, D.S., 1990, A theory of predation based on agency problems in financial contracting, American Economic Review 80, 93-106.

Boot, A.W.A., and Thakor, A.V., 1993, Security design, Journal of Finance 48, 1349-1378.

Boot, A.W.A., Greenbaum, S.I., and Thakor, A.V., 1993, Reputation and discretion in financial contracting, American Economic Review 83, 1165-1183.

Boot, A.W.A., and Thakor, A.V., 2000, Can relationship banking survive competition? Journal of Finance 55, 679-713.

Broecker, T., 1990, Credit-worthiness tests and interbank competition, Econometrica 58, 429452.

Cetorelli, N., and Gambera, M., 2001, Banking market structure, financial dependence and growth, Journal of Finance 56, 617-648.

DeMarzo, P.M., and Duffie, D., 1999, A liquidity-based model of security design, Econometrica 67, 65-99.

DeMarzo, P.M., and Fishman, M.J., 2000, Optimal long-term financial contracting with privately observed cash flows, mimeo, Stanford University.

Diamond, D., 1984, Financial intermediation and delegated monitoring, Review of Economic Studies 51, 393-414. 
Fulghieri, P., and Lukin, D., 2001, Information production, dilution costs, and optimal security design, Journal of Financial Economis 61, 3-42.

Gale, D., and Hellwig, M.F., 1985, Incentive-compatible debt contracts: The one-period problem, Review of Economic Studies 52, 647-663.

Hart, O.D., and Moore, J.H., 1998, Default and renegotiation: A dynamic model of debt, Quarterly Journal of Economics 113, 1-41.

Hauswald, R., and Marquez, R., 2001, Information technology and financial services competition, forthcoming in Review of Financial Studies.

Holmström, B.R., and Tirole, J., 1997, Financial intermediation, loanable funds, and the real sector, Quarterly Journal of Economics 112, 663-691.

Inderst, R., and Müller, H.M., 2002a, Internal versus external financing: An optimal contracting approach, forthcoming in Journal of Finance.

Inderst, R., and Müller, H.M., 2002b, The effect of capital market characteristics on the value of start-up firms, mimeo, New York University.

Innes, R., 1990, Limited liability and incentive contracting with ex-ante action choices, Journal of Economic Theory 52, 45-67.

Manove, M., Padilla, A.J., and Pagano, M., 2001, Collateral vs. project screening: A model of lazy banks, Rand Journal of Economics 32, 726-44.

Maskin, E., and Tirole, J., 1990, The principal-agent relationship with an informed principal: The case of private values, Econometrica 58, 379-409.

Maskin, E., and Tirole, J., 1992, The principal-agent relationship with an informed principal, II: Common values, Econometrica 60, 1-42.

Milgrom, P.R., 1981, Good news and bad news: Representation theorems and applications, Bell Journal of Economics 12, 380-391.

Mizruchi, M.S., and Sterns, L.B., 1993, Corporate financing: Social and economic determinants, in: Explorations in Economic Sociology, R. Swedberg, ed., New York: Russel Sage Foundation. 
Myers, S.C., and Majluf, N.S., 1984, Corporate financing and investment decisions when firms have information investors do not have, Journal of Financial Economics 13, 187-221.

Nachman, D.C., and Noe, T.H., 1994, Optimal design of securities under asymmetric information, Review of Financial Studies 7, 1-44.

Petersen, M.A., and Rajan, R.G., 1994, The benefits of lending relationships: Evidence from small business data, Journal of Finance 49, 3-37.

Petersen, M.A., and Rajan, R.G., 2002, Does distance still matter? The information revolution in small business lending

Rajan, R.G., 1992, Insiders and outsiders: The choice between informed and arm's length debt, Journal of Finance 47, 1367-1399.

Saunders, A., and Allen, L., 2002, Credit risk measurement. Second edition. New York: John Wiley \& Sons.

Saunders, A., and Thomas, H., 2001, Financial institutions mangement. Second Canadian edition. Toronto: McGraw-Hill Ryerson.

Sharpe, S., 1990, Asymmetric information, bank lending and implicit contracts: A stylized model of customer relationships, Journal of Finance 45, 1069-1087.

Stein, J.C., 2002, Information production and capital allocation: Decentralized vs. hierarchical firms, Journal of Finance 57, 1891-1921.

Townsend, R.M., 1979, Optimal contracts and competitive markets with costly state verification, Journal of Economic Theory 21, 265-293.

von Thadden, E.-L., 1995, Long-term contracts, short-term investments and monitoring, Review of Economic Studies 62, 557-575.

von Thadden, E.-L., 1998, Asymmetric information, bank lending and implicit contracts: The winner's curse, mimeo, University of Lausanne.

Yosha, O., 1995, Information disclosure costs and the choice of financing source, Journal of Financial Intermediation 4, 3-20. 